Informatika i sistemy upravleniya. - 2019. - No. 2(60). - P. 3-15.

Grigorev Yu.A. (grigorev@bmstu.ru), Ermakov O.Yu.

Bauman Moscow State Technical University

\title{
LAMBDA-ARCHITECTURE OF THE SYSTEM WITH THE SERVICE LEVEL BASED ON METADATA FOR THE APPROXIMATE QUERY PROCESSING
}

A new approach to the lambda architecture has been proposed, which eliminates the need for batch submission at the service level. The structure of the metadata and the AQP-LA method (Approximate Query Processing in the systems based on Lambda Architecture) are also proposed enabling to handle the approximate query processing of the batch level data and increasing the accuracy of database attributes aggregated values calculations. According to the results of experiments, AQP-LA method is twice as good as Sapprox in $\delta$-accuracy in $\varepsilon$-accuracy.

Keywords: lambda-architecture, stream processing, approximate query processing, Sapprox.

DOI:10.22250/isu.2019.60.3-15

For citation:

Grigorev Yu.A., Ermakov O.Yu. LAMBDA-ARCHITECTURE OF THE SYSTEM WITH THE SERVICE LEVEL BASED ON METADATA FOR THE APPROXIMATE QUERY PROCESSING // Informatika i sistemy upravleniya. - 2019. - No. 2(60). - P. 3-15. 